\title{
Research Paper: Comparing the Frequency of Self- Medication Among Physical Therapy Students of Major Private Colleges of Karachi, Pakistan
}

\author{
Sanish Sumble ${ }^{1}$ (D, Mazhar Ali Bhutto ${ }^{2 *}$ (D), Muhammad Sarfraz Khan ${ }^{3}$, Hina Sumble ${ }^{4}$,Abdul Rehman Sher Muhammad ${ }^{5}$, Arsalan Abdullah ${ }^{5}$
}

1. Chief of Staff, Dow University of Health Sciences, Sindh Government Hospital Liaquatabad, Karachi, Pakistan.

2. School of Rehabilitation Science, Tehran University of Medical Science, Tehran, Iran.

3. IPMR, Department of Physiotherapy, Dow University of Health Sciences, Karachi, Pakistan.

4. Department of Senior Physiotherapist-Physiotherapy, Dar ul Sukun, Bhittai Colony Karachi, Pakistan.

5. Department of Rehabilitation, Isra University, karachi, Pakistan.

$\begin{aligned} & \text { Use your device to san } \\ & \text { and read the article online }\end{aligned}$
$\begin{aligned} & \text { oftation: Sumble S, Bhutto MA, Sarfraz Khan M, Sumble H, Sher Muhammad AR, Abdullah A. Comparing the Frequency } \\ & \text { of Self-Medication Among Physical Therapy Students of Major Private Colleges of Karachi, Pakistan. Journal of Modern Reha- } \\ & \text { bilitation. 2019; 13(3):147-152. http://dx.doi.org/10.32598/JMR.13.3.147 }\end{aligned}$
doli http://dx.doi.org/10.32598/JMR.13.3.147

\section{(1) (8)}

Article info:

Received: 13 Feb 2019

Accepted: 05 Jun 2019

Available Online: 01 Jul 2019

\section{Keywords:}

Self-medication,

Undergraduate students,

Physical therapy, Karachi

\section{A B S T RACT}

Introduction: Taking medication without a doctor's prescription is not always harmful and may reduce the cost and save the time. In Pakistan, homemade remedies and spiritual faith are the first line of treatment of minor illnesses. This study was carried on undergraduate Physical Therapy students of Karachi, Pakistan.

Materials and Methods: Was a cross-sectional study, conducted on 250 undergraduate Physical Therapy students from major private and semiprivate colleges of Karachi, Pakistan. The participants were chosen by simple random sampling method. The research was done using $95 \%$ confidence interval.

Results: Our result shows that medication use without doctor's advice is a frequent practice among the undergraduate Physical Therapy students of major private and semi-private institutes of Karachi, Pakistan. It was observed that $5 \%, 21 \%, 18 \%, 4 \%, 27 \%, 25 \%$ of the students were taking self-medication on daily, weekly, fortnight, monthly, yearly and occasional basis, respectively.

Conclusion: Headache is the main ailment for which students are practicing self-medication.

\section{* Corresponding Author:}

Mazhar Ali Bhutto, PhD.

Address: School of Rehabilitation Science, Tehran University of Medical Science, Tehran, Iran.

Tel: +92 (33) 32254743

E-mail: mazharalibhutto@hotmail.com 


\section{Introduction}

M

edication use without prescription is a matter of concern for health related organizations worldwide. Everyone experiences insignificant pains and momentary symptoms in his life now and then. Everybody responds quite separately to solve these issues, and methods can vary from complete neglecting the symptom to prompt seeking of medical help. Selftreatment by taking homemade, traditional, and natural things is a common way of treating minor illnesses. Particularly in Pakistan, seeking over the counter medication, home-based treatments and spiritual faith, are immediate responses by majority of population against illnesses [1]. Besides, antimicrobial medication without consulting a doctor is also common in most of the less developed countries that results in the health related liability, hazards in these Countries [2].

Medication use without passing the proper path of diagnosis and treatment cannot always be considered as harmful. Medications categorized as "buying without written by doctor" might often help in emergency and they are less expensive for the buyer, too. In majority of the villages and remote areas where there is a lack of health care facilities, peoples are practicing self-use medications for minor problems [3].

Medication use without prescription involves the use of pharmaceutical products by the user to manage selfdocumented disorder or problem. People also use medications suggested by the concerned doctor for chronic or seasonal problems or diseases. Medication self-use has great risks factors. Incorrect patient self-diagnosis, knowledge, behavior and self-use of medication among health education students failure of taking accurate health treatment on time, wrong selection of therapy, unable to identify specific drug hazards, occasional but adverse side effects, fail to identify or self-knowing about disease indication, its interaction, uses, disuses, alarming and red flags precaution, inappropriate route and over dosage, hazards of dependence and abuse [4].

A study on health education students in Bahrain also few Saudi students were considered in research survey, suggested that these candidates were not having enough knowledge regarding accurate Medication use, information related to drug use and disuse was not appropriate. The students focus and thinking towards self use of medication was in favor of not using but practically the use of self selecting and diagnosing was openly present [5]. The work of self use of medication in university health related undergraduates is highly imperative as students are part $\mathrm{f}$ the people who are most littered and they have information related to diseases, systems and there treatment. I is also matter of thinking that this population will prescribe the drug in future, to treat the Public [6]. Use of Self selected medicine was mostly drugs from the conventional pain killer to broad spectrum antibiotics. However it is difficult to stop self use of medicine, but it is responsibility of drug controlling officials and health related professionals spread awareness among students about effects and side effects of medication without concerning to doctors [7].

\section{Methods}

A 'Cross Sectional survey' conducted among undergraduate Physical Therapy candidates major private and semiprivate colleges of Karachi, Pakistan. Inclusion criteria: 1. Pakistani Nationality holding students; 2. Age between 18 and 25 years; and 3. Undergraduate Physical therapy students.Exclusion criteria: 1 . Students who were not enrolled in any university; 2 . Foreign nationality holder students; 3 . Age below 18 years and above 25 years. Time and place of study: The total study period was 6 months (March 2017-August 2017), Karachi Pakistan Sampling technique: Sample size is calculated as $25 \mathrm{O}$ at $95 \%$ Confidence interval and 0.05 margin of blunder.Data collection: A self-administered questionnaire was given to the students after informing the purpose of study and has taken written consent from the students. Ethical rules: Consent form had been signed by the participants containing permission and information regarding this research activity while focusing on ethical rules.Statistical analysis: Data was entered and analyzed by using SPSS V. 17.0. Frequency and percentages were taken out as a part of descriptive statistics. At the time of recruitment participants were requested to fill the 'Questionnaire' based on prevalence, attitudes and practices towards self-medication.

\section{Results}

Majority of the students were found practicing selfmedication at yearly and occasional basis .It was observed that students were taking self-medication on daily, weekly, fortnight, monthly, yearly and occasional basis with percentages $5 \%, 21 \%, 18 \%, 4 \%, 27 \% 25 \%$ respectively as shown in Table 1, Figure 1 shows Frequency of self-medication in percentage. and Table 2, Figure 2 shows the ailments for which students were taking self-medication. 
Figure 2 shows the element on $\mathrm{X}$ axis while percentage of use of self-medication on $\mathrm{Y}$ axis.

\section{Discussion}

This study was conducted on undergraduate Physical therapy students in Karachi, Pakistan. A similar study conducted on self-medication among pharmacy students revealed alarming results. In the study, it was found that $63 \%$ of candidates used psychostimulant medications to boost performance in exams and academics. In addition, the study indicated almost all candidates $(96 \%)$ accepted that they are using antidepressants to manage their stress $(\mathrm{P}<0.05)[8]$.

In our study, we found that students practice selfmedication for the symptomatic treatment of conditions like headache $(76 \%)$, depression $(7 \%)$, fever $(6 \%)$, insomnia (6\%), allergies (3\%), and miscellaneous conditions $(2 \%)$. The results have been shown in Table 2 . In another study in Palestine, 1581 out of 1600 questionnaires related to self-medications were filled by medical students. The response rate of the questionnaire in the study was $98.8 \%$, and the average age of the partici- pants was 19.9 years and the participants were mostly females $(63.3 \%)$ [9].

The psycho-social aspects of the people of India is very much similar to those of Pakistan. A study conducted in urban Pondicherry, India reported a significantly high number of self-medication among medical students $(\mathrm{P}<0.05)$. Fever and temperature $(31 \%)$, headache (19\%), and abdomen related complaints (16.7\%) were the most common reasons for self-medication among the medical students. Taking advise by quoting problems to pharmacist $(38.1 \%)$ was mostly adopted method to buy and use medicine by the population [10].

It is worth mentioning that self-medication is not only practiced by the urban population of Pakistan but also in rural areas of the country. In a study conducted in Punjab, Pakistan, a total number of 4348 drugs were purchased for self-medication without physician's prescription by 3037 buyers (15.2\% of targeted population). Among this population, 873 (28.7\%) willingly took part in an oral survey. A huge number of the drug buyers $(81.2 \%)$ and $90.9 \%$ of the buyers who participated in the survey were males. On average, every pharmacy sold

Table 1. Frequency of self-medication in percentage

\begin{tabular}{ccc}
\hline Valid & $\%$ & Cumulative Percent \\
\hline Daily & 0.5 & 0.5 \\
\hline Weekly & 0.21 & 0.26 \\
\hline Fortnight & 0.18 & 0.44 \\
\hline Monthly & 0.4 & 0.48 \\
\hline Yearly & 0.27 & 0.75 \\
\hline Occasionally & 0.25 & 0.001 \\
\hline
\end{tabular}

Table 2. Ailments for which self-medication was being used and percentages

\begin{tabular}{ccc}
\hline Ailments & $\%$ & Cumulative Percent \\
\hline Headache & 0.76 & 0.76 \\
\hline Depression & 0.7 & 0.83 \\
\hline Fever & 0.6 & 0.89 \\
\hline Insomnia & 0.6 & 0.95 \\
\hline Allergies & 0.3 & 0.98 \\
\hline Others & 0.2 & 0.001 \\
\hline
\end{tabular}




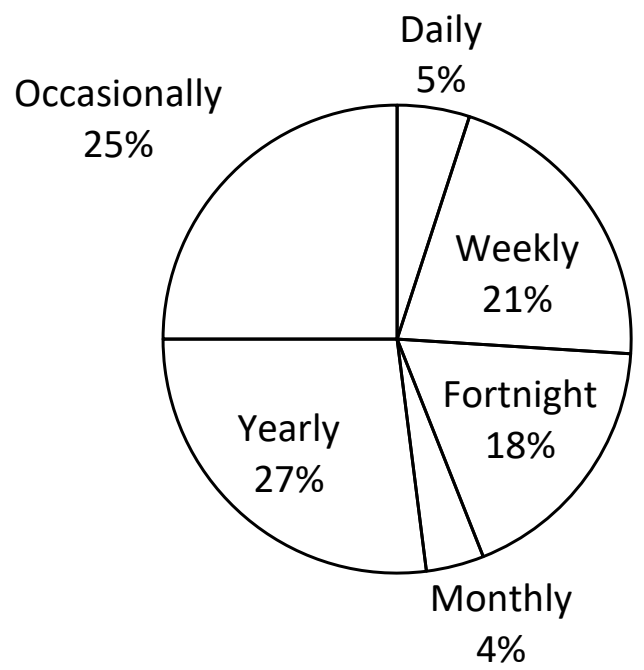

Figure 1. Frequency of self-medication in percentage

7.9 drugs without prescription every day To an average of 5.5 customers. Many of them (28.9\%) were metric in their education [11].

Self-Medication has a lot of side effects. For example, medications for fever and pain killers in excess doses can lead to liver failure and Paracetamol toxicity. Medication by self- selection can be prove dangerous as it has many hazards just like overdose, long term continuous use of medication, drug interactions and poly pharmacy, Valsartan is drug for blood pressure [12]. It is very good and effective when used in accurate dose. The main focus is the over usage of the drug might cause hypo-tension, and this can progress to heart, liver and kidney failure. The World Health Organization (WHO) has also indicated that medication self-selection can be good to prevent and manage those problems that do not need medical consultation [5].
Self-medication has problem of wrong diagnosis, wrong medication use and side effects. About advantages self-medication one research mentioned that selfmedication is emerging as continuous up going and important part within medical care as it push users near greater independence in taking the decisions related to treat minor problems it also decreases by the burden on their pockets while visiting consultants over and over again thereby promoting empowerment [13].

Robinson found in his research that disadvantages of self-medication are anxiety, phobia [14]. Among young population with mood or irritation related disorders, living in a medical marijuana law state which is related with medication self-selection use with marijuana [15]. The $69.2 \%$ practiced among all took self-medication minimum once. The self-medication were greater in females, in younger population [16], were the results of

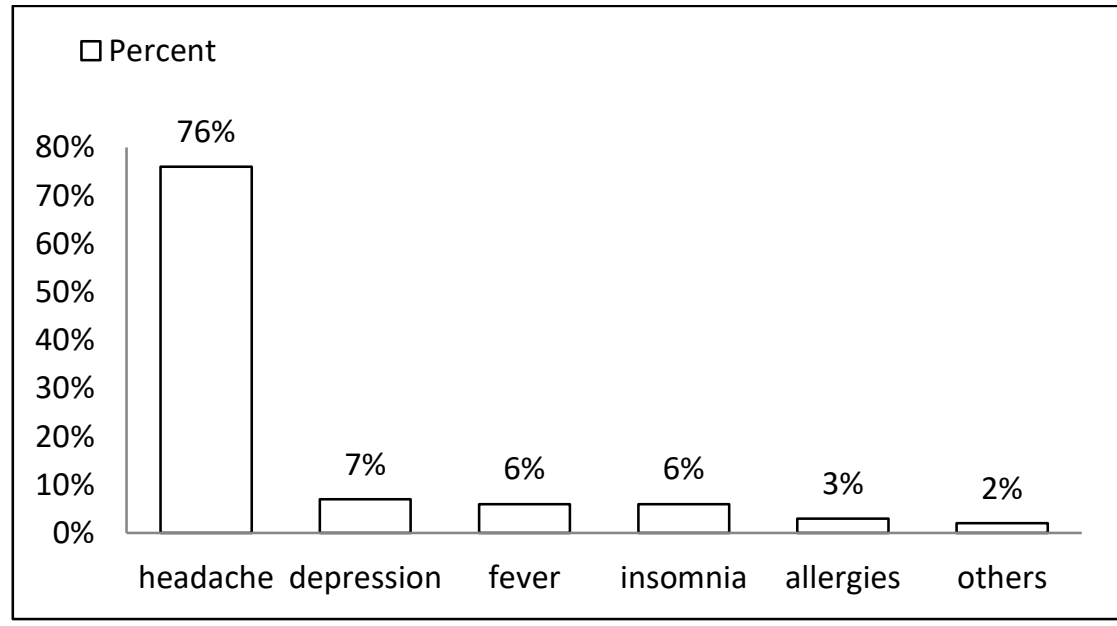

Figure 2. Ailments for which self-medication was being used 
the cross-sectional survey at Paris. Self-medication is associated with many glitches as incorrect self-diagnosis, poor treatment of a disease, which can result in disease progression and complications [17].

Most drugs can have significant undesirable effects. This may result in serious clinical effects with possible life-threatening complications. Therefore, the diagnosis by the physician is very important for the proper treatment. The pharmacist in a community pharmacy has a significant role in recommending drugs for self-medication. The pharmacist should distinguish between patients for whom pharmacists could recommend the drugs and patients who should be fortified to consult physicians. A study carried out in Faisalabad, Pakistan concluded that self-medication is more common among males $(64.5 \%)$ as compared to females (58.5\%) [18]. It is interesting to know that yoga concrete the way for physical, mental and spiritual wellbeing provides the individual with holistic health [19].

\section{Conclusion}

Our result cleared the picture that self-medication is frequent practice among the undergraduate Physical Therapy students of major private and semi-private institutes of Karachi, Pakistan. It was observed that mostly students didn't have sufficient knowledge about medicines and its uses. We should create awareness about the common diseases and symptoms like headache, fever and their diagnosis with proper medication to avoid adverse effects associated with these self-medications

\section{Ethical Considerations}

\section{Compliance with ethical guidelines}

Prior to study, participants signed a written consent form and they were assured of the confidentiality of their information.

\section{Funding}

This research did not receive any specific grant from funding agencies in the public, commercial, or not-forprofit sectors.

\section{Authors contributions}

All authors contributed in preparing this paper.

\section{Conflict of interest}

The authors declared no conflict of interest

\section{References}

[1] Anwar M, Green JA, Norris P, Pukhari NI. Self-medication home remedies, and spiritual healing: Common responses to everyday symptoms in Pakistan. Health Psychology and Behavioral Medicine. 2015; 3(1):281-95. [DOI:10.1080/21642850 .2015.1088387]

[2] Ocan M, Obuku EA, Bwanga F, Akena D, Richard S, OgwalOkeng J, et al. Household antimicrobial self-medication: a systematic review and meta-analysis of the burden, risk factors and outcomes in developing countries. BMC Public Health. 2015; 15:742. [DOI:10.1186/s12889-015-2109-3] [PMID] [PMCID]

[3] Kalyan VS, Sudhakar K, Srinivas P, Sudhakar GVS, Pratap KVNR, Madhavi Padma T. Evaluation of self-medication practices among undergraduate dental students of tertiary care teaching dental hospital in South India. Journal of Education and Ethics in Dentistry. 2013; 3(1):21-5. [DOI:10.4103/0974-7761.126939]

[4] Alkatheri MO. Prevalence study of self-medication practice used among nursing workers in ibn sina hospital in coast hadhramout governate-yemen. 2017; 7(2):192-203. [DOI: 10.20959/wjpr20182-10756]

[5] James H, Handu SS, Al Khaja KA, Otoom S, Sequeira RP Evaluation of the knowledge, attitude and practice of selfmedication among first-year medical students. Med Princ Pract. 2006; 15(4):270-5. [DOI:10.1159/000092989] [PMID]

[6] Surabhi G, Meenakshi J. Study of self-medication pattern in undergraduate students of subharti medical college, meerut (UP). Journal of Advance Researches in Biological Sciences. 2013; 5(3):266-70

[7] Abay SM, Amelo W. Assessment of self-medication practices among medical, pharmacy, and health science students in gondar university, ethiopia.Journal of Young Pharmacists. 2010; 2(3):306-10. [DOI:10.4103/0975-1483.66798] [PMID] [PMCID]

[8] Abbas A, Ahmed FR, Yousuf R, Khan N, Nisa ZU, Ali SI, et al. Prevalence of self-medication of psychoactive stimulants and antidepressants among undergraduate pharmacy students in twelve Pakistani cities. Tropical Journal of Pharmaceutical Research. 2015; 14(3):527-32. [DOI:10.4314/tjpr.v14i3.23]

[9] Sawalha AF. Assessment of self-medication practice among University students in palestine: Therapeutic and toxicity implications. IUG Journal of Natural Studies. 2007; 15(2):67-82.

[10] Selvaraj K, Kumar SG, Ramalingam A. Prevalence of self-medication practices and its associated factors in urban puducherry, India. Perspectives in Clinical Research. 2014; 5(1):32-6. [DOI:10.4103/2229-3485.124569] [PMID] [PMCID]

[11] Aziz MM, Masood I, Yousaf M, Saleem H, Ye D, Fang Y. Pattern of medication selling and self-medication practices: A study from Punjab, Pakistan. PLoS One. 2018; 13(3):e0194240. [DOI:10.1371/journal.pone.0194240] [PMID] [PMCID]

[12] Mumtaz Y, Jahangeer A, Mujtaba T, Zafar S, Adnan S. Self medication among university students of Karachi. Journal of Liaquat University of Medical and Health Sciences. 2011; 10(03):102-5.

[13] Hughes CM, McElnay JC, Fleming GF. Benefits and risks of self medication. Drug Safety, 2001. 24(14):1027-37. [DOI:10.2165/00002018-200124140-00002] [PMID] 
[14] Robinson J, Sareen J, Cox BJ, Bolton JM. Role of self-medication in the development of comorbid anxiety and substance use disorders: A longitudinal investigation. Archives Of General Psychiatry. 2011; 68(8):800-7. [DOI:10.1001/archgenpsyy chiatry.2011.75] [PMID]

[15] Sarvet AL, Wall MM, Keyes KM, Olfson M, Cerdá M, Hasin DS. Self-medication of mood and anxiety disorders with marijuana: Higher in states with medical marijuana laws. Drug and Alcohol Dependence. 2018; 186:10-5. [DOI:10.1016/j. drugalcdep.2018.01.009] [PMID] [PMCID]

[16] Garofalo L, Di Giuseppe G, Angelillo IF. Self-medication practices among parents in Italy. BioMed Research International. 2015; 2015:580650. [DOI:10.1155/2015/580650] [PMID] [PMCID]

[17] Al-Hussaini M, Mustafa S, Ali S. Self-medication among undergraduate medical students in Kuwait with reference to the role of the pharmacist. Journal of Research in Pharmacy Practice. 2014; 3(1):23-7. [DOI:10.4103/2279-042X.132706] [PMID] [PMCID]

[18] Bhardwaj A. Holistic health through Yogic lifestyle [Internet]. 2015. [Cited 2015 Jun 12]. Available from: https:/ / www. liveholistic.in/holistic-health/

[19] Shankar SP, Ramya N. Pattern of physical activity, diet, sleep and yoga in health care physicians: A study from a tertiary care hospital, Pondicherry. International Journal of Advances in Medicine. 2017; 4:1394-7. [DOI:10.18203/23493933.ijam20174290] 